\title{
Identification, Genotyping and Antimicrobial Susceptibility Testing of Brucella spp. Isolated from Livestock in Egypt
}

\author{
Aman Ullah Khan ${ }^{1,2,3}{ }^{\mathbb{D}}$, Waleed S. Shell ${ }^{4}$, Falk Melzer ${ }^{1}$, Ashraf E. Sayour ${ }^{5}$, \\ Eman Shawkat Ramadan ${ }^{6}$, Mandy C. Elschner ${ }^{1}$, Amira A. Moawad 1,2,7 (D), Uwe Roesler ${ }^{2}$, \\ Heinrich Neubauer ${ }^{1}$ and Hosny El-Adawy ${ }^{1,8, *(D)}$ \\ 1 Institute of Bacterial Infections and Zoonoses, Friedrich-Loeffler-Institut, 07743 Jena, Germany; \\ AmanUllah.Khan@fli.de (A.U.K.); falk.melzer@fli.de (F.M.); Mandy.Elschner@fli.de (M.C.E.); \\ amira.moawad@fli.de (A.A.M.); heinrich.neubauer@fli.de (H.N.) \\ 2 Institute for Animal Hygiene and Environmental Health, Free University of Berlin, 14163 Berlin, Germany; \\ Uwe.Roesler@fu-berlin.de \\ 3 Department of Pathobiology, College of Veterinary and Animal Sciences, 35200 Jhang, Pakistan \\ 4 Central Laboratory for Evaluation of Veterinary Biologics, Agricultural Research Center, \\ 11517 Abbasaia-Cairo, Egypt; tarikwaleedshell@hotmail.com \\ 5 Department of Brucellosis, Animal Health Research Institute, Agricultural Research Center, \\ 12618 Dokki-Giza, Egypt; shoofa@dr.com \\ 6 Animal Reproduction Research Institute, Agricultural Research Center, 12556 Al Ahram-Giza, Egypt; \\ emanramadan1311971@gmail.com \\ 7 Provincial Laboratory, Institute of Animal Health Research, 35516 Mansoura, Egypt \\ 8 Faculty of Veterinary Medicine, Kafr Elsheikh University, 33516 Kafr El-Sheikh, Egypt \\ * Correspondence: hosny.eladawy@fli.de
}

Received: 23 October 2019; Accepted: 16 November 2019; Published: 22 November 2019

\begin{abstract}
Brucellosis is a highly contagious zoonosis worldwide with economic and public health impacts. The aim of the present study was to identify Brucella (B.) spp. isolated from animal populations located in different districts of Egypt and to determine their antimicrobial resistance. In total, 34-suspected Brucella isolates were recovered from lymph nodes, milk, and fetal abomasal contents of infected cattle, buffaloes, sheep, and goats from nine districts in Egypt. The isolates were identified by microbiological methods and matrix-assisted laser desorption ionization time-of-flight mass spectrometry (MALDI-TOF MS). Differentiation and genotyping were confirmed using multiplex PCR for B. abortus, Brucella melitensis, Brucella ovis, and Brucella suis (AMOS) and Bruce-ladder PCR. Antimicrobial susceptibility testing against clinically used antimicrobial agents (chloramphenicol, ciprofloxacin, erythromycin, gentamicin, imipenem, rifampicin, streptomycin, and tetracycline) was performed using E-Test. The antimicrobial resistance-associated genes and mutations in Brucella isolates were confirmed using molecular tools. In total, 29 Brucella isolates (eight B. abortus biovar 1 and 21 B. melitensis biovar 3) were identified and typed. The resistance of $B$. melitensis to ciprofloxacin, erythromycin, imipenem, rifampicin, and streptomycin were $76.2 \%, 19.0 \%, 76.2 \%, 66.7 \%$, and $4.8 \%$, respectively. Whereas, $25.0 \%, 87.5 \%, 25.0 \%$, and $37.5 \%$ of $B$. abortus were resistant to ciprofloxacin, erythromycin, imipenem, and rifampicin, respectively. Mutations in the rpoB gene associated with rifampicin resistance were identified in all phenotypically resistant isolates. Mutations in gyr A and gyrB genes associated with ciprofloxacin resistance were identified in four phenotypically resistant isolates of $B$. melitensis. This is the first study highlighting the antimicrobial resistance in Brucella isolated from different animal species in Egypt. Mutations detected in genes associated with antimicrobial resistance unravel the molecular mechanisms of resistance in Brucella isolates from Egypt. The mutations in the rpoB gene in phenotypically resistant $B$. abortus isolates in this study were reported for the first time in Egypt.
\end{abstract}


Keywords: Brucella; Egypt; antimicrobial resistance; resistance-associated genes; mutation

\section{Introduction}

Brucellosis is considered as a common bacterial zoonotic disease of high prevalence in countries of the Middle East and the Mediterranean region, as well as some parts of Central and South America, Africa, and Asia [1,2]. Brucellosis is caused by bacteria of various species of the genus Brucella (B.) that are genetically highly related $[3,4]$. Brucella is a Gram negative, facultative intracellular pathogen classically causing infections in sheep and goats (B. melitensis), rams (B. ovis), bovines (B. abortus), canines (B. canis), pigs (B. suis), and rodents (B. neotomae) $[5,6]$. Brucellosis also affects terrestrial wildlife (B. microti) and marine mammals (B. ceti and B. pinnipedialis) [7]. However, the cross infection of animal species with brucellae has also been reported [8]. Brucellosis in livestock is causing high economic losses to livestock industry due to poor health, debility and loss of quality livestock products [9]. In humans, brucellosis causes severe acute febrile illness that becomes chronic if left untreated [10].

In developing countries, brucellosis is common but neglected disease, which has been endemic in Egypt for thousands of years and is present with a high prevalence in animals today [11-14]. Prevalence ranges from $2.47 \%$ to $26.66 \%$ in various livestock populations and this has a great socio-economic impact [15]. In Egypt, B. abortus, B. suis and B. melitensis strains were isolated from livestock having high levels of phylogenetic variability within each species [12]. The incidence of human brucellosis is $0.28-95$ per 100,000 inhabitants per year in Egypt $[16,17]$. Humans get infected via the ingestion of contaminated raw milk, unpasteurized dairy products, handling of infected animals, animal discharges or dealing with Brucella cultures [18,19].

The diagnosis of brucellosis is still challenging and usually relies on serological tests [20], which are applied in vitro (milk or blood). Exceptionally, in vivo (allergic tests) are used. The isolation of brucellae and detection of Brucella DNA by PCR are the methods that allow definitive diagnosis [21].

Although confirmation of the disease is achieved by bacterial culture and identification, Brucella is difficult to grow and bacterial culturing is time consuming. Additionally, this method poses a risk to laboratory personnel and requires specific biosafety measures [22]. Hence, culture and biochemical typing remain the "gold standard" for the diagnosis of Brucella infection [23], including biochemical tests like $\mathrm{CO}_{2}$ requirement, $\mathrm{H}_{2} \mathrm{~S}$ production, and dye sensitivity. Urease, oxidase, and catalase tests are also used for the typing of Brucella spp. [24]. A comparatively new method like matrix-assisted laser desorption ionization time-of-flight mass spectrometry (MALDI-TOF MS) has emerged for microbiological identification [25]. It is an economical, easy, rapid and accurate method based on the automated analysis of the mass distribution of bacterial proteins [26]. A recently published study indicates that MALDI-TOF MS can accurately identify $99.5 \%$ and $97 \%$ of Brucella strains at the genus and species level, respectively that minimizing laboratory hazards. However, there are limitations in terms of sub-species level identification [27]. Brucella identification and species differentiation can be accomplished using genus-specific Brucella PCR (B4/B5), AMOS-PCR, and Bruce-ladder PCR [28-32].

The intracellular location of brucellae in reticuloendothelial cells and their predilection sites (e.g., bone) limit the penetration of most antibiotics. Antimicrobial regimes with quinolones, doxycycline, rifampicin, streptomycin, and aminoglycoside alone or in combination are used to treat brucellosis [33]. Regular treatment failure and numerous reports of relapses of brucellosis following therapy exist ranging from $5 \%$ to $15 \%$ in uncomplicated cases [34]. Recently, the antimicrobial resistance in Brucella is emerging in brucellosis endemic regions of the world (e.g., Egypt, Qatar, Iran, Malaysia, and China) [34].

There is no proper legislation in Egypt regulating the use of antimicrobials. Some compounds such as quinolones, tetracycline, beta-lactams, aminoglycosides and imipenem are still overused non-therapeutically in Egypt to treat various human infections [35-37]. This improper use of antimicrobials results in the emergence of multidrug resistant bacteria [38-41]. The use of antimicrobials 
in farm animals to promote growth or as prophylaxis also contributes to the development of resistant bacteria and plays a key role in their spread along the food chain [42]. Antimicrobial resistance in zoonotic pathogens is an additional risk because it will limit disease treatment options in public health and veterinary settings [43]. None of the available studies highlights detailed antimicrobial susceptibility patterns of Brucella isolates from livestock in Egypt.

The use of antimicrobial susceptibility testing is the solution for appropriate control and treatment of brucellosis [44,45]. Micro-dilution and/or gradient strip (E-test) methods are used to establish minimum inhibitory concentration (MIC) for antimicrobials $[45,46]$. PCR assays and the subsequent sequencing of genes associated with resistance are used to identify the genetic bases of resistance [47-49].

Resistance to commonly used antimicrobials is mediated by mutations of rpoB gene (rifampicin), gyr A, gyr B, parC, parE genes (quinolones), erm, mef, msr (macrolides) or the presence of tet genes (tetracyclines), mecA (beta-lactams) and floA (trimethoprim) [50]. Mutations in the rpoB and gyr A genes may occur naturally or can be induced in vitro $[45,47,51,52]$.

This study aimed to isolate, identify and biotype Brucella strains from livestock in various regions of Egypt. Antimicrobial resistance and its genetic basis are to be investigated in the gained Brucella isolates.

\section{Materials and Methods}

\subsection{Isolation and Identification}

A total of 34 suspected Brucella isolates were recovered from clinical specimens of lymph nodes, milk and fetal stomach contents from infected cattle, buffaloes, sheep and goats located in Giza, Beheria, Asyut, Qalyubia, Beni-Suef, Ismailia, Dakahlia, and Monufia governorates/districts in Egypt (Table 1).

Bacterial isolation and identification were performed in Biological Safety Level-3 (BSL-3) laboratory. Isolates were inoculated on calf blood agar, Brucella medium and Brucella selective medium plates (Oxoid $\mathrm{GmbH}$, Wesel, Germany) at $37^{\circ} \mathrm{C}$ in the absence and presence of 5-10\% CO2 for up to 2 weeks. Typically, round, glistening, pinpoint and honey drop-like cultures were picked and stained with Gram and modified Ziehl-Neelsen staining (MZN) methods. Subsequent biochemical tests, motility test, hemolysis on blood agar and agglutination with monospecific sera were performed [24,53]. Isolates were stored at $-20^{\circ} \mathrm{C}$ for further processing.

\section{Identification by MALDI-TOF MS}

Bacterial identification was additionally carried out using MALDI-TOF MS as described previously [27,54]. Briefly, pure cultures of suspected Brucella were obtained by incubating inoculated chocolate PolyViteX (PVX) agar plates (bioMérieux, Marcy-l'Étoile, France) for $48 \mathrm{~h}$ at $37{ }^{\circ} \mathrm{C}$ in the presence of $5 \% \mathrm{CO}_{2}$. Samples were reliably inactivated in Biological Safety Level-3 laboratory. Approximately 10 colonies from culture medium were suspended in $50 \mu \mathrm{L}$ of sterile HPLC water and mixed carefully. Formic acid $(v / v 70 \%)$ was added for the inactivation of brucellae and for extraction of proteins. Then, $1 \mu \mathrm{L}$ of tested sample and Brucella reference strains were added onto spots of a steel target plate. After inactivation, the plate was dried at room temperature followed by the addition of $0.5 \mu \mathrm{L}$ of $100 \%$ ethanol to each well. Finally, spots were overlaid with $1 \mu \mathrm{L}$ of reconstituted alpha-cyano-4-hydroxycinnamic acid (Bruker Daltonics, Billerica, MA, USA).

Spectra were acquired with an Ultraflex instrument (Bruker Daltonics GmbH, Bremen, Germany). Analysis was done with the Biotyper 3.1 software (Bruker Daltonics $\mathrm{GmbH}$, Germany) as per the manufacturer's instructions to exclude spectra with outlier peaks or anomalies.

Logarithmic score values (0-3.0) were determined by automatically calculating the proportion of matching peaks and peak intensities between the test spectrum and the reference spectra in the database. The identification was considered reliable when the score between 2.3 and 3.0. A logarithmic score of 1.7-2.299 was reported as 'probable genus identification', indicating that identification was 
reliable only at the genus level. When the logarithmic score was $<1.7$, the spectrum was reported as 'not reliable identification', indicating that sample could not be identified.

\subsection{Genomic DNA Extraction and Purification}

DNA was extracted from heat inactivated pure Brucella culture (biomass) using the HighPure PCR Template Preparation Kit (Roche Diagnostics, Mannheim, Germany) according to the manufacturer's instructions. DNA quantity and purity were determined using a NanoDrop ${ }^{\mathrm{TM}} 1000$ spectrophotometer (Thermo Fisher Scientific, Wilmington, USA).

\subsection{Molecular Identification and Differentiation}

The presence of the Brucella genus-specific bscp31 gene [55] and Brucella-specific insertion sequence 711 (IS711) [29] was investigated for Brucella genus identification. Briefly, PCR was performed using $25 \mu \mathrm{L}$ reaction mixture containing 18.3 $\mu \mathrm{L}$ HPLC water, $2.5 \mu \mathrm{L}$ 10x PCR buffer (Genaxxon bioscience $\mathrm{GmbH}$, Ulm, Germany), $1 \mu \mathrm{l}$ of 10mM dNTP (Thermo Fisher Scientific, USA), $1 \mu \mathrm{L}$ each forward (5'-TGG CTC GGT TGC CAA TAT CAA-3') and reverse primer (5' CGC GCT TGC CTT TCA GGT CTG-3') (Jena Bioscience, Germany), $0.2 \mu \mathrm{L}$ of $5 \mathrm{U} / \mu \mathrm{L}$ Taq-polymerase (Genaxxon bioscience $\mathrm{GmbH}$, $\mathrm{Ulm}$, Germany) and $1 \mu \mathrm{L}$ DNA template.

PCR condition was initiated by initial denaturation at $93^{\circ} \mathrm{C}$ for $5 \mathrm{~min}$, followed by 35 cycles of denaturation at $90^{\circ} \mathrm{C}$ for $60 \mathrm{~s}$, annealing at $60{ }^{\circ} \mathrm{C}$ for $60 \mathrm{~s}$ and elongation at $72{ }^{\circ} \mathrm{C}$ for $60 \mathrm{~s}$ and final elongation step at $72{ }^{\circ} \mathrm{C}$ for $5 \mathrm{~min}$. PCR products (223 bp) were analyzed on $1.5 \%$ agarose gel, stained with ethidium bromide, and visualized under UV light.

The AMOS-PCR was performed to differentiate Brucella species [29,32] followed by a multiplex Bruce-ladder PCR assay for strain and biovar typing $[30,56]$. The list of primers and primer sequences for AMOS-PCR and Bruce-ladder PCR were geared from previously published [29] and [30], respectively. Briefly, for AMOS-PCR, PCR was performed using $25 \mu \mathrm{L}$ reaction mixture containing 9.5 $\mu \mathrm{L}$ HPLC water, $12.5 \mu \mathrm{L}$ of $2 x$ Qiagen Master mix (Qiagen, Germany), $1 \mu \mathrm{L}$ of 10 pmol primer mix and $2 \mu \mathrm{L}$ DNA template. Initial denaturation at $95^{\circ} \mathrm{C}$ for $5 \mathrm{~min}$, was followed by 30 cycles of denaturation at $95^{\circ} \mathrm{C}$ for $60 \mathrm{~s}$, annealing at $58^{\circ} \mathrm{C}$ for $2 \mathrm{~min}$ and elongation at $72{ }^{\circ} \mathrm{C}$ for $2 \mathrm{~min}$ and a final elongation step at $72{ }^{\circ} \mathrm{C}$ for $5 \mathrm{~min}$. The Bruce-ladder PCR was performed using $12.5 \mu \mathrm{L}$ reaction mixture containing $4.25 \mu \mathrm{L}$ HPLC water, $6.25 \mu \mathrm{l}$ of 2x Qiagen Master mix (Qiagen, Germany), $1 \mu \mathrm{L}$ of $2 \mathrm{pmol} / \mu \mathrm{L}$ primer mix and 1 $\mu \mathrm{L}$ DNA template. Initial denaturation at $95^{\circ} \mathrm{C}$ for $15 \mathrm{~min}$, was followed by 25 cycles of denaturation at $94{ }^{\circ} \mathrm{C}$ for $30 \mathrm{~s}$, annealing at $58^{\circ} \mathrm{C}$ for $90 \mathrm{~s}$, elongation at $72^{\circ} \mathrm{C}$ for $3 \mathrm{~min}$ and a final elongation step at $72{ }^{\circ} \mathrm{C}$ for $10 \mathrm{~min}$.

The PCR products from each PCR were separated by electrophoresis using $1.5 \%$ agarose gels (120 V for $60 \mathrm{~min}$ for conventional and AMOS-PCR and $130 \mathrm{~V}$ for $60 \mathrm{~min}$ for Bruce-ladder PCR). Gels were stained with ethidium bromide and photographed using a gene snap camera (Syngene Pvt Ltd., Cambridge, UK).

\subsection{Antimicrobial Susceptibility Testing}

The antimicrobial susceptibility of B. melitensis and B. abortus isolates was performed against eight clinically relevant antimicrobial agents (chloramphenicol, ciprofloxacin, erythromycin, gentamicin, imipenem, rifampicin, streptomycin and tetracycline) using gradient strip method (E-test, bioMerieux, Marcy L'Etoile, France) as described previously [48]. Briefly, a suspension of bacteria adjusted to 0.5 McFarland standard units was inoculated on Mueller-Hinton plates (Oxoid GmbH, Wesel, Germany) supplemented with $5 \%$ sheep blood and the gradient strips were applied. The plates were incubated at $37{ }^{\circ} \mathrm{C}$ with $5 \% \mathrm{CO}_{2}$ for $48 \mathrm{~h}$ before reading. As MIC breakpoints for clinically used antimicrobials are not yet established for brucellae, the guidelines for slow-growing bacteria (Haemophilus influenzae) were used as an alternative [57]. Quality control assays were performed using E. coli (161008BR3642, DSM 1103, ATCC 25922). The susceptibility profiles of Brucella isolates are presented as resistant and susceptible using minimum inhibitory concentrations (MIC), $\mathrm{MIC}_{50}$ and $\mathrm{MIC}_{90}$. The interpretations 
were performed using CLSI (The Clinical and Laboratory Standards Institute) [57] and EUCAST (The European Committee on Antimicrobial Susceptibility Testing) [58] using the criteria for slow growing bacteria. For rifampin, the strains were also classified as intermediate (Table 2).

\subsection{Molecular Detection of Antimicrobial Resistance-Associated Genes}

The PCR assays were performed as described previously $[47,49,52,59]$ to detect the antimicrobial resistance-associated genes, i.e., cat $\mathrm{B}$, gyr $\mathrm{A}$ and $g y r \mathrm{~B}, r p o \mathrm{~B}$, Aac genes and tet genes for chloramphenicol, ciprofloxacin, rifampicin, streptomycin, gentamicin and tetracycline, respectively (Supplementary Table S1). The primers used for amplification of the $r p o B$ gene were designed by using submitted sequences for the rpoB gene of B. abortus (accession number AY562181) [47]. PCR was performed using $25 \mu \mathrm{L}$ reaction mixture containing $2 x$ Qiagen Mastermix, 10 pmol each forward and reverse primer (Table 1) and $5 \mu \mathrm{l}$ DNA template. PCR was carried out by initial denaturation at $95{ }^{\circ} \mathrm{C}$ for $10 \mathrm{~min}$, followed by 35 cycles of denaturation at $95^{\circ} \mathrm{C}$ for $45 \mathrm{~s}$, annealing (temperatures for each primer are given in Table 1) for $60 \mathrm{~s}$, elongation at $72{ }^{\circ} \mathrm{C}$ for $60 \mathrm{~s}$ and a final elongation step at $72{ }^{\circ} \mathrm{C}$ for $10 \mathrm{~min}$. Twenty microliters of each reaction mixture were analyzed by gel electrophoresis ( $1 \%$ agarose gel with ethidium bromide).

\subsection{PCR Amplicon Sequencing and Data Analysis}

Amplified PCR products for $g y r \mathrm{~A}, g y r \mathrm{~B}$ and $r p o \mathrm{~B}$ genes were purified using Qiagen QIAquick Gel extraction kit (Qiagen, Germany) and sent for sequencing (Eurofins Genomics Germany GmbH, Ebersberg, Germany). All consensus sequences were aligned and compared to the reference Brucella genes obtained from NCBI for detection and evaluation of nucleotide diversity and mutations using the software Geneious ${ }^{\circledR}$ R11.1.5 (https://www.geneious.com). The sequences of gyrA (CP034103 and AE017223), gyrB (CP007760 and SDWB01000001) and rpoB (AY562181 and AY540346) genes of B. melitensis and B. abortus were geared from Gene bank and used as reference. Amino acid sequences were determined along with nucleotide sequences to identify missense mutations using BLAST.

\section{Results}

\subsection{Microbiological Identification}

Based on microbiological and biochemical characteristics, 21 strains were typed as B. melitensis biovar 3, eight strains were B. abortus biovar 1 and five samples were identified as Achromobacter species (Table 1). The results of MALDI-TOF MS confirmed five isolates as Achromobacter species while the remaining 29 isolates were identified as Brucella species (Table 1).

\subsection{Molecular Identification and Differentiation}

Brucella DNA of 24 isolates from cattle, three from buffaloes, one from a sheep and one from a goat were amplified with the genus specific assay. AMOS-PCR and Bruce-ladder PCR differentiated these 21 isolates as B. melitensis ( 17 from cattle, two from buffaloes, 1 from a sheep and 1 from a goat) and 8 isolates as B. abortus (seven from cattle and one from a buffalo). All isolates were confirmed as field strains (Table 1).

\subsection{Antimicrobial Susceptibility Profiling}

The in vitro MIC values against eight antimicrobial agents of all 29 Brucella isolates were determined by the gradient strip method (E-test). The MIC values along with $\mathrm{MIC}_{50}$ and $\mathrm{MIC}_{90}$ are summarized in Table 2.

In this study, $76.19 \%, 19.04 \%, 76.19 \%, 66.66 \%$, and $4.76 \%$ of the B. melitensis isolates were resistant to ciprofloxacin, erythromycin, imipenem, rifampicin/rifampin and streptomycin, respectively. While, $25 \%, 87.5 \%, 25 \%$, and $37.5 \%$ of B. abortus isolates were phenotypically resistant to ciprofloxacin, erythromycin, imipenem and rifampicin/rifampin, respectively. All 29 Brucella isolates were sensitive 
to chloramphenicol, gentamicin, and tetracycline. Four isolates of B. melitensis (19.04\%) and one B. abortus isolate showed multidrug resistance against ciprofloxacin (fluoroquinolones), erythromycin (macrolides), imipenem (carbapenems) and rifampicin (ansamycins).

\subsection{Detection of Antimicrobial Resistance-Associated Genes and Mutations}

Genes associated with antimicrobial resistance $(\operatorname{cat} \mathrm{B}, \mathrm{Aac}$ and $\operatorname{tet}(\operatorname{tet} \mathrm{A}, \operatorname{tet} \mathrm{B}, \operatorname{tet} \mathrm{M}$ and $\operatorname{tet} \mathrm{O})$ conferring resistance to chloramphenicol, streptomycin/gentamicin and tetracycline, respectively) were not identified either in resistant or sensitive isolates. The $g y r \mathrm{~A}, g y r \mathrm{~B}$ and $r p o \mathrm{~B}$ genes were amplified in all isolates.

Mutations in rpoB gene associated with a rifampicin-resistant B. melitensis and B. abortus phenotypes were detected at different positions (Table 3).

Mutations in gyrA gene associated with phenotypic-ciprofloxacin resistance were detected at positions 167 (ATG to AGG/methionine to arginine), 197 (CCC to CGC/proline to arginine), 202 (CGC to $\underline{A G C / a r g i n i n e ~ t o ~ s e r i n e), ~} 235$ (GGT to $\underline{\mathrm{CGT} / g l y c i n e ~ t o ~ a r g i n i n e), ~} 941$ (GCC to GAC/alanine to aspartic acid), 944 (GTG to GAG/valine to glutamic acid), $944-945$ (GTG to GGA/valine to glycine), 946 (GCC to TCC/alanine to serine) and 962 (AAC to ACC/asparagine to threonine) in B. melitensis (Table 4).

Three-point mutations were also detected in gyrB gene at position 1141 (AAG to GAG/Lysine to Glutamine), 1144 (ATC to $\underline{C T C / I s o l e u c i n e ~ t o ~ l e u c i n e) ~ a n d ~} 1421$ (TCA to TTA/Serine to Leucine) in phenotypically resistant $B$. melitensis isolates (Table 4).

Repeated mutations were detected at positions 676,677 (TAC to $\underline{\mathrm{CTC}}$ /tyrosine to leucine) and 1435 (AAG to $\underline{C A G / l y s i n e ~ t o ~ g l u t a m i n e) ~ i n ~ t h e ~ r p o B ~ g e n e ~ o f ~ p h e n o t y p i c ~ r e s i s t a n t ~} B$. melitensis isolates while the same was recorded at position 2890 (CGT to GGT/arginine to glycine) in the rpoB gene of B. abortus isolates. No mutation was detected in gyrA and gyrB gene of B. abortus strains. 
Table 1. Microbiological and molecular identification of Brucella spp. isolated from animal species in Egypt.

\begin{tabular}{|c|c|c|c|c|c|c|c|c|c|c|c|c|}
\hline \multirow{2}{*}{$\begin{array}{c}\text { Sample } \\
\text { ID }\end{array}$} & \multirow{2}{*}{$\begin{array}{l}\text { Animal } \\
\text { Species }\end{array}$} & \multirow{2}{*}{$\begin{array}{c}\text { Origin of } \\
\text { Sample }\end{array}$} & \multirow[t]{2}{*}{ Type of Sample } & \multicolumn{3}{|c|}{ Growth with $\mathrm{CO}_{2}$} & \multicolumn{4}{|c|}{ Slide Agglutination A-M-R-Serum } & \multirow[t]{2}{*}{ MALDI-TOF MS } & \multirow{2}{*}{$\begin{array}{c}\text { Molecular } \\
\text { Identification }\end{array}$} \\
\hline & & & & ${ }^{\mathrm{c}}$ Bruc & ${ }^{\mathrm{d}}$ Brusel & ${ }^{\mathbf{e}}$ BBA & A & $\mathbf{M}$ & $\mathbf{R}$ & Result & & \\
\hline 18RB17227 & Cattle & Giza & Lymph node & + & + & + & $a_{+v e}$ & +ve & $\mathrm{b}_{-\mathrm{ve}}$ & B. melitensis 3 & Brucella spp. (B. abortus) & B. melitensis \\
\hline 18RB17228 & Cattle & Giza & Lymph node & + & + & + & $+\mathrm{ve}$ & $+\mathrm{ve}$ & $-\mathrm{ve}$ & B. melitensis 3 & Brucella spp. (B. abortus) & B. melitensis \\
\hline 18RB17229 & Cattle & Giza & Lymph node & + & + & + & $+\mathrm{ve}$ & $+\mathrm{ve}$ & - ve & B. melitensis 3 & Brucella melitensis & B. melitensis \\
\hline 18RB17230 & Cattle & Giza & Lymph node & + & + & + & $+\mathrm{ve}$ & +ve & $-\mathrm{ve}$ & B. melitensis 3 & Brucella spp. (B. melitensis) & B. melitensis \\
\hline 18RB17231 & Cattle & Giza & Lymph node & + & + & + & $-\mathrm{ve}$ & -ve & $-\mathrm{ve}$ & ${ }^{*} \mathrm{NA}$ & Achromobacter spp. & -ve \\
\hline 18RB17232 & Cattle & Giza & Lymph node & + & + & + & $-\mathrm{ve}$ & -ve & $-v e$ & $\mathrm{NA}$ & Achromobacter spp. & -ve \\
\hline 18RB17233 & Cattle & Giza & Lymph node & $+/-$ & $+/-$ & $+/-$ & $+\mathrm{ve}$ & -ve & - ve & B. abortus 1 & B. abortus & B. abortus \\
\hline 18RB17234 & Cattle & Giza & Lymph node & + & + & + & -ve & -ve & - ve & $\mathrm{NA}$ & Achromobacter spp. & -ve \\
\hline 18RB17235 & Cattle & Giza & Lymph node & + & + & + & +ve & $+\mathrm{ve}$ & $-\mathrm{ve}$ & B. melitensis 3 & Brucella spp. (B. microti) & B. melitensis \\
\hline 18RB17236 & Cattle & Giza & Lymph node & + & + & + & +ve & $+\mathrm{ve}$ & - ve & B. melitensis 3 & Brucella spp. (B. melitensis) & B. melitensis \\
\hline 18RB17237 & Cattle & Giza & Lymph node & + & + & + & $-\mathrm{ve}$ & -ve & $-\mathrm{ve}$ & NA & Achromobacter spp. & -ve \\
\hline 18RB17238 & Cattle & Giza & Lymph node & + & + & + & +ve & -ve & $-\mathrm{ve}$ & B. abortus 1 & Brucella spp. (B. microti) & B. melitensis \\
\hline 18RB17239 & Cattle & Giza & Lymph node & + & + & + & $-\mathrm{ve}$ & -ve & $-\mathrm{ve}$ & NA & Achromobacter spp. & -ve \\
\hline 18RB17240 & Cattle & Beheira & Lymph node & + & + & + & $+\mathrm{ve}$ & $+\mathrm{ve}$ & - ve & B. melitensis 3 & Brucella spp. (B. microti) & B. melitensis \\
\hline 18RB17241 & Cattle & Beheira & Lymph node & + & + & + & $+\mathrm{ve}$ & $+\mathrm{ve}$ & - ve & B. melitensis 3 & Brucella spp. (B. microti) & B. melitensis \\
\hline 18RB17242 & Cattle & Beheira & Lymph node & $+/-$ & $+/-$ & $+/-$ & $+\mathrm{ve}$ & -ve & $-\mathrm{ve}$ & B. abortus 1 & B. abortus & B. abortus \\
\hline 18RB17243 & Cattle & Beheira & Lymph node & $+/-$ & $+/-$ & $+/-$ & $+\mathrm{ve}$ & -ve & $-\mathrm{ve}$ & B. abortus 1 & B. abortus & B. abortus \\
\hline 18RB17244 & Buffalo & Asyut & Lymph node & + & + & + & $+\mathrm{ve}$ & +ve & $-\mathrm{ve}$ & B. melitensis 3 & Brucella spp. (B. abortus) & B. melitensis \\
\hline 18RB17245 & Buffalo & Asyut & Lymph node & $+/-$ & $+/-$ & $+/-$ & +ve & $-\mathrm{ve}$ & $-\mathrm{ve}$ & B. abortus 1 & B. abortus & B. abortus \\
\hline 18RB17246 & Goat & Beni-Suef & Lymph node & + & + & + & $+\mathrm{ve}$ & +ve & $-\mathrm{ve}$ & B. melitensis 3 & Brucella spp. (B. microti) & B. melitensis \\
\hline 18RB17247 & Cattle & Asyut & Lymph node & + & + & + & $+\mathrm{ve}$ & +ve & $-\mathrm{ve}$ & B. melitensis 3 & Brucella spp. (B. melitensis) & B. melitensis \\
\hline 18RB17248 & Cattle & Qalyubia & Lymph node & + & + & + & +ve & $+\mathrm{ve}$ & $-v e$ & B. melitensis 3 & Brucella spp. (B. microti) & B. melitensis \\
\hline 18RB17249 & Cattle & Qalyubia & Lymph node & + & + & + & +ve & $+\mathrm{ve}$ & $-\mathrm{ve}$ & B. melitensis 3 & Brucella spp. (B. melitensis) & B. melitensis \\
\hline 18RB17250 & Sheep & Beni-Suef & Lymph node & + & + & + & +ve & + ve & $-v e$ & B. melitensis 3 & Brucella spp. (B. melitensis) & B. melitensis \\
\hline 18RB17251 & Cattle & Beni-Suef & Lymph node & + & + & + & $+\mathrm{ve}$ & $+\mathrm{ve}$ & $-v e$ & B. melitensis 3 & Brucella spp. (B. microti) & B. melitensis \\
\hline 18RB17252 & Cattle & Ismailia & Lymph node & + & + & + & $+\mathrm{ve}$ & $+\mathrm{ve}$ & - ve & B. melitensis 3 & Brucella spp. (B. melitensis) & B. melitensis \\
\hline
\end{tabular}


Table 1. Cont.

\begin{tabular}{|c|c|c|c|c|c|c|c|c|c|c|c|c|}
\hline \multirow[t]{2}{*}{$\begin{array}{c}\text { Sample } \\
\text { ID }\end{array}$} & \multirow[t]{2}{*}{$\begin{array}{l}\text { Animal } \\
\text { Species }\end{array}$} & \multirow[t]{2}{*}{$\begin{array}{c}\text { Origin of } \\
\text { Sample }\end{array}$} & \multirow[t]{2}{*}{ Type of Sample } & \multicolumn{3}{|c|}{ Growth with $\mathrm{CO}_{2}$} & \multicolumn{4}{|c|}{ Slide Agglutination A-M-R-Serum } & \multirow[t]{2}{*}{ MALDI-TOF MS } & \multirow[t]{2}{*}{$\begin{array}{c}\text { Molecular } \\
\text { Identification }\end{array}$} \\
\hline & & & & ${ }^{\mathrm{c}}$ Bruc & ${ }^{\mathrm{d}}$ Brusel & ${ }^{\mathrm{e}} \mathrm{BBA}$ & A & $\mathbf{M}$ & $\mathbf{R}$ & Result & & \\
\hline 18RB17253 & Cattle & Ismailia & Lymph node & + & + & + & + ve & $+\mathrm{ve}$ & -ve & B. melitensis 3 & Brucella spp. (B. abortus) & B. melitensis \\
\hline 18RB17254 & Cattle & Ismailia & Lymph node & + & + & + & $+\mathrm{ve}$ & $+\mathrm{ve}$ & $-\mathrm{ve}$ & B. melitensis 3 & Brucella spp. & B. melitensis \\
\hline 18RB17255 & Cattle & Beheira & $\begin{array}{l}\text { Fetal stomach } \\
\text { content }\end{array}$ & $+/-$ & $+/-$ & $+/-$ & +ve & - ve & -ve & B. abortus 1 & B. abortus & B. abortus \\
\hline 18RB17256 & Cattle & Dakahlia & Lymph node & $+/-$ & $+/-$ & $+/-$ & +ve & - ve & -ve & B. abortus 1 & B. abortus & B. abortus \\
\hline 18RB17257 & Cattle & Monufia & Lymph node & $+/-$ & $+/-$ & $+/-$ & $+\mathrm{ve}$ & - ve & $-\mathrm{ve}$ & B. abortus 1 & B. abortus & B. abortus \\
\hline 18RB17258 & Cattle & Monufia & Milk & + & + & + & + ve & + ve & $-\mathrm{ve}$ & B. melitensis 3 & Brucella spp. (B. abortus) & B. melitensis \\
\hline 18RB17259 & Cattle & Qalyubia & Lymph node & $+/-$ & $+/-$ & $+/-$ & $+\mathrm{ve}$ & - ve & -ve & B. abortus 1 & B. abortus & B. abortus \\
\hline 18RB17260 & Buffalo & Qalyubia & Lymph node & + & + & + & $+\mathrm{ve}$ & + ve & -ve & B. melitensis 3 & Brucella spp. (B. microti) & B. melitensis \\
\hline
\end{tabular}

Table 2. Antimicrobial resistance profiles of 21 B. melitensis and 8 B. abortus isolated from livestock species in Egypt against 8 clinically used antibiotics using E-test. Breakpoint and Minimal Inhibitory Concentration $\left(\mathrm{MIC}_{50}, \mathrm{MIC}_{90}\right)$ for B. melitensis and B. abortus used in this study according to CLSI and EUCAST recorded for H. influenzae $[57,58]$ were provided.

\begin{tabular}{|c|c|c|c|c|c|c|c|c|c|c|}
\hline \multirow[b]{2}{*}{ Antibiotic } & \multirow[b]{2}{*}{ Class } & \multicolumn{3}{|c|}{ Breakpoints } & \multicolumn{3}{|c|}{ B. melitensis } & \multicolumn{3}{|c|}{ B. abortus } \\
\hline & & $\begin{array}{c}\text { Sensitive } \\
(\mathrm{mg} / \mathrm{L})\end{array}$ & $\begin{array}{l}\text { Intermedium } \\
(\mathrm{mg} / \mathrm{L})\end{array}$ & $\begin{array}{c}\text { Resistant } \\
(\mathrm{mg} / \mathrm{L})\end{array}$ & R (\%) & $\begin{array}{l}\mathrm{MIC}_{50} \\
(\mathrm{mg} / \mathrm{L})\end{array}$ & $\begin{array}{l}\mathrm{MIC}_{90} \\
(\mathrm{mg} / \mathrm{L})\end{array}$ & R (\%) & $\begin{array}{l}\mathrm{MIC}_{50} \\
(\mathrm{mg} / \mathrm{L})\end{array}$ & $\begin{array}{l}\mathrm{MIC}_{90} \\
(\mathrm{mg} / \mathrm{L})\end{array}$ \\
\hline Chloramphenicol & Phenicols & $\leq 2$ & 4 & $\geq 8$ & 0.0 & 1 & 2 & 0.0 & 0.25 & 0.5 \\
\hline Ciprofloxacin & Fluoroquinolones & $\leq 0.06$ & - & $>0.06$ & 76.19 & 0.12 & 0.25 & 25.0 & 0.06 & 0.06 \\
\hline Erythromycin & Macrolides & - & - & $\geq 16$ & 19.04 & 4 & 8 & 87.5 & 32 & 32 \\
\hline Gentamicin & Aminoglycosides & - & - & $\leq 4$ & 0.0 & 11 & 11 & 0.0 & 0.12 & 0.5 \\
\hline Imipenem & Carbapenems & $\leq 2$ & - & $>2$ & 76.19 & 8 & 8 & 25.0 & 1 & 4 \\
\hline Rifampicin & Ansamycins & $\leq 1$ & 2 & $\geq 4$ & 66.66 & 4 & 8 & 37.5 & 2 & 4 \\
\hline Streptomycin & Aminoglycosides & - & - & $\leq 16$ & 4.76 & 1 & 2 & 0.0 & 0.25 & 0.5 \\
\hline Tetracycline & Tetracyclines & $\leq 2$ & 4 & $\geq 8$ & 0.0 & 0.06 & 0.12 & 0.0 & 0.03 & 0.12 \\
\hline
\end{tabular}

-. Not determined 
Table 3. Detection of mutations in rpoB gene associated with rifampicin resistance in B. melitensis and B. abortus.

\begin{tabular}{|c|c|c|c|c|c|c|}
\hline ID & Brucella spp. & RIF Resistance & Mutation Sites & Mutation & Amino Acid Change & $\begin{array}{c}\text { NCBI } \\
\text { (Accession No.) }\end{array}$ \\
\hline 18RB17227 & B. melitensis & 4 & $\begin{array}{c}676,677 \\
1816 \\
1818 \\
1820,1822 \\
1824,1825 \\
1826,1828 \\
1829,1831 \\
1835,1837 \\
1838 \\
1842,1843\end{array}$ & $\begin{array}{l}\text { TAC to CTC } \\
\text { GAT to GAA } \\
\text { GTC to GCC } \\
\text { GTT to ATA } \\
\text { TAC to TTT } \\
\text { CTG to GTT } \\
\text { TCG to GAC } \\
\text { ATG to GGC } \\
\text { GAA to AAA } \\
\text { GAA to GGT }\end{array}$ & $\begin{array}{c}\text { Tyrosine to leucine } \\
\text { Aspartic acid to glutamic acid } \\
\text { Valine to alanine } \\
\text { Valine to isoleucine } \\
\text { Tyrosine to phenylalanine } \\
\text { Leucine to valine } \\
\text { Serine to aspartic acid } \\
\text { Methionine to glycine } \\
\text { Glutamic acid to lysine } \\
\text { Glutamic acid to glycine }\end{array}$ & $\begin{array}{l}\text { MN544028, } \\
\text { MN544042, } \\
\text { MN544056, } \\
\text { MN544070, } \\
\text { MN544084 }\end{array}$ \\
\hline 18RB17228 & B. melitensis & 4 & $\begin{array}{c}676,677 \\
3901,3902\end{array}$ & $\begin{array}{l}\text { TAC to CTC } \\
\text { TAC to ACC }\end{array}$ & $\begin{array}{l}\text { Tyrosine to leucine } \\
\text { Tyrosine to threonine }\end{array}$ & $\begin{array}{l}\text { MN544029, } \\
\text { MN544043, } \\
\text { MN544057, } \\
\text { MN544071, } \\
\text { MN544085 }\end{array}$ \\
\hline 18RB17229 & B. melitensis & 4 & $\begin{array}{c}676,677 \\
1011 \\
1456,1458 \\
1787 \\
2491\end{array}$ & $\begin{array}{l}\text { TAC to CTC } \\
\text { AAC to AGC } \\
\text { GAA to AAG } \\
\text { AAG to ACG } \\
\text { ACC to CCC }\end{array}$ & $\begin{array}{l}\text { Tyrosine to leucine } \\
\text { Asparagine to serine } \\
\text { Glutamic acid to lysine } \\
\text { Lysine to threonine } \\
\text { Threonine to proline }\end{array}$ & $\begin{array}{l}\text { MN544030, } \\
\text { MN544044, } \\
\text { MN544058, } \\
\text { MN544072, } \\
\text { MN544086 }\end{array}$ \\
\hline 18RB17230 & B. melitensis & 8 & $\begin{array}{c}676,677 \\
1435 \\
1798,1799 \\
1801,1802 \\
1804,1806 \\
1807 \\
2209,2210\end{array}$ & $\begin{array}{l}\text { TAC to CTC } \\
\text { AAG to CAG } \\
\text { GGC to AAC } \\
\text { AAG to GGG } \\
\text { GTG to CTT } \\
\text { ACG to TCG } \\
\text { ATC to TCC }\end{array}$ & $\begin{array}{l}\text { Tyrosine to leucine } \\
\text { Lysine to glutamine } \\
\text { Glycine to asparagine } \\
\text { Lysine to glycine } \\
\text { Valine to leucine } \\
\text { Threonine to serine } \\
\text { Isoleucine to serine }\end{array}$ & $\begin{array}{l}\text { MN544031, } \\
\text { MN544045, } \\
\text { MN544059, } \\
\text { MN544073, } \\
\text { MN544087 }\end{array}$ \\
\hline 18RB17235 & B. melitensis & $>8$ & $\begin{array}{c}676,677 \\
1469\end{array}$ & $\begin{array}{l}\text { TAC to CTC } \\
\text { GTC to GGC }\end{array}$ & $\begin{array}{l}\text { Tyrosine to leucine } \\
\text { Valine to glycine }\end{array}$ & $\begin{array}{l}\text { MN544032, } \\
\text { MN544046, } \\
\text { MN544060, } \\
\text { MN544074, } \\
\text { MN544087 }\end{array}$ \\
\hline
\end{tabular}


Table 3. Cont.

\begin{tabular}{|c|c|c|c|c|c|c|}
\hline ID & Brucella spp. & RIF Resistance & Mutation Sites & Mutation & Amino Acid Change & $\begin{array}{c}\text { NCBI } \\
\text { (Accession No.) }\end{array}$ \\
\hline 18RB17236 & B. melitensis & 8 & 676,677 & TAC to CTC & Tyrosine to leucine & $\begin{array}{l}\text { MN544033, } \\
\text { MN544047, } \\
\text { MN544061, } \\
\text { MN544075, } \\
\text { MN544089 }\end{array}$ \\
\hline 18RB17238 & B. melitensis & 16 & $\begin{array}{c}677 \\
1780 \\
1786,1788 \\
2869,2871\end{array}$ & $\begin{array}{l}\text { TAC to TTC } \\
\text { TAT to GAT } \\
\text { AAG to CAA } \\
\text { CGT to GGG }\end{array}$ & $\begin{array}{l}\text { Tyrosine to phenylalanine } \\
\text { Tyrosine to aspartic acid } \\
\text { Lysine to glutamine } \\
\text { Arginine to glycine }\end{array}$ & $\begin{array}{l}\text { MN544034, } \\
\text { MN544048, } \\
\text { MN544062, } \\
\text { MN544076, } \\
\text { MN544090 }\end{array}$ \\
\hline 18RB17240 & B. melitensis & 16 & 2494,2496 & TCG to CTC & Serine to leucine & $\begin{array}{l}\text { MN544035, } \\
\text { MN544049, } \\
\text { MN544063, } \\
\text { MN544077, } \\
\text { MN544091 }\end{array}$ \\
\hline 18RB17241 & B. melitensis & $6(8)$ & $\begin{array}{c}1435 \\
2870,2871\end{array}$ & $\begin{array}{l}\text { AAG to CAG } \\
\text { CGT to CCG }\end{array}$ & $\begin{array}{l}\text { Lysine to glutamine } \\
\text { Arginine to proline }\end{array}$ & $\begin{array}{l}\text { MN544036, } \\
\text { MN544050, } \\
\text { MN544064, } \\
\text { MN544078, } \\
\text { MN544092 }\end{array}$ \\
\hline 18RB17246 & B. melitensis & 4 & $\begin{array}{c}676,678 \\
1436,1437 \\
2870 \\
3898 \\
3901\end{array}$ & $\begin{array}{l}\text { TAC to CTT } \\
\text { AAG to ACA } \\
\text { CGT to CCT } \\
\text { TAC to AAC } \\
\text { ACG to CCG }\end{array}$ & $\begin{array}{l}\text { Tyrosine to leucine } \\
\text { Lysine to threonine } \\
\text { Arginine to proline } \\
\text { Tyrosine to asparagine } \\
\text { Threonine to proline }\end{array}$ & $\begin{array}{l}\text { MN544037, } \\
\text { MN544051, } \\
\text { MN544065, } \\
\text { MN544079, } \\
\text { MN544093 }\end{array}$ \\
\hline
\end{tabular}


Table 3. Cont.

\begin{tabular}{|c|c|c|c|c|c|c|}
\hline ID & Brucella spp. & RIF Resistance & Mutation Sites & Mutation & Amino Acid Change & $\begin{array}{c}\text { NCBI } \\
\text { (Accession No.) }\end{array}$ \\
\hline 18RB17249 & B. melitensis & 4 & $\begin{array}{c}1435,1437 \\
2170 \\
2203,2205 \\
2869 \\
3152,3153 \\
3154,3156 \\
3157 \\
\end{array}$ & $\begin{array}{l}\text { AAG to GTA } \\
\text { GGC to CGC } \\
\text { ATC to TTT } \\
\text { CGT to GGT } \\
\text { GTG to GGT } \\
\text { CAG to GCA } \\
\text { CGC to AGC }\end{array}$ & $\begin{array}{c}\text { Lysine to valine } \\
\text { Glycine to arginine } \\
\text { Isoleucine to phenylalanine } \\
\text { Arginine to glycine } \\
\text { Valine to glycine } \\
\text { Glutamine to alanine } \\
\text { Arginine to serine }\end{array}$ & $\begin{array}{l}\text { MN544038, } \\
\text { MN544052, } \\
\text { MN544066, } \\
\text { MN544080, } \\
\text { MN544094 }\end{array}$ \\
\hline 18RB17253 & B. melitensis & 4 & $\begin{array}{l}1435 \\
1745\end{array}$ & $\begin{array}{l}\text { AAG to CAG } \\
\text { GCC to GGC }\end{array}$ & $\begin{array}{l}\text { Lysine to glutamine } \\
\text { Alanine to glycine }\end{array}$ & $\begin{array}{l}\text { MN544039, } \\
\text { MN544053, } \\
\text { MN544067, } \\
\text { MN544081, } \\
\text { MN544095 }\end{array}$ \\
\hline 18RB17258 & B. melitensis & 6 & $\begin{array}{c}676,677 \\
2501,2502\end{array}$ & $\begin{array}{l}\text { TAC to CTC } \\
\text { CAC to CCA }\end{array}$ & $\begin{array}{l}\text { Tyrosine to leucine } \\
\text { Histidine to proline }\end{array}$ & $\begin{array}{l}\text { MN544040, } \\
\text { MN544054, } \\
\text { MN544068, } \\
\text { MN544082, } \\
\text { MN544096 }\end{array}$ \\
\hline 18RB17260 & B. melitensis & 4 & $\begin{array}{c}1435 \\
3670,3672\end{array}$ & $\begin{array}{l}\text { AAG to CAG } \\
\text { CAG to TAT }\end{array}$ & $\begin{array}{l}\text { Lysine to glutamine } \\
\text { Glutamine to tyrosine }\end{array}$ & $\begin{array}{l}\text { MN544041, } \\
\text { MN544055, } \\
\text { MN544069, } \\
\text { MN544083, } \\
\text { MN544097 }\end{array}$ \\
\hline 18RB17233 & B. abortus & 4 & $\begin{array}{c}703,704 \\
709,710 \\
1457,1458 \\
1460 \\
2512 \\
2515,2517 \\
2890,2892 \\
3123 \\
3124,3125\end{array}$ & $\begin{array}{l}\text { ACT to CTT } \\
\text { ACC to CAC } \\
\text { AAG to ACA } \\
\text { GAA to GGA } \\
\text { ACC to CCC } \\
\text { TCG to CTC } \\
\text { CGT to GGG } \\
\text { GAC to GAG } \\
\text { GAC to ATC }\end{array}$ & $\begin{array}{l}\text { Threonine to leucine } \\
\text { Threonine to histidine } \\
\text { Lysine to threonine } \\
\text { Glutamic acid to glycine } \\
\text { Threonine to proline } \\
\text { Serine to leucine } \\
\text { Arginine to glycine } \\
\text { Aspartic acid to glutamic acid } \\
\text { Aspartic acid to isoleucine }\end{array}$ & $\begin{array}{l}\text { MN544013, } \\
\text { MN544016, } \\
\text { MN544019, } \\
\text { MN544022, } \\
\text { MN544025 }\end{array}$ \\
\hline
\end{tabular}


Table 3. Cont.

\begin{tabular}{|c|c|c|c|c|c|c|}
\hline ID & Brucella spp. & RIF Resistance & Mutation Sites & Mutation & Amino Acid Change & $\begin{array}{c}\text { NCBI } \\
\text { (Accession No.) }\end{array}$ \\
\hline 18RB17242 & B. abortus & $>4$ & $\begin{array}{c}698,699 \\
1457,1458 \\
1460 \\
1789 \\
1801 \\
2887 \\
2890 \\
\end{array}$ & $\begin{array}{l}\text { TAC to TTT } \\
\text { AAG to ACA } \\
\text { GAA to GGA } \\
\text { ATC to GTC } \\
\text { TAT to GAT } \\
\text { GAG to AAG } \\
\text { CGT to GGT }\end{array}$ & $\begin{array}{l}\text { Tyrosine to phenylalanine } \\
\text { Tyrosine to threonine } \\
\text { Glutamic acid to glycine } \\
\text { Isoleucine to valine } \\
\text { Tyrosine to aspartic acid } \\
\text { Glutamic acid to lysine } \\
\text { Arginine to glycine }\end{array}$ & $\begin{array}{l}\text { MN544014, } \\
\text { MN544017, } \\
\text { MN544020, } \\
\text { MN544023, } \\
\text { MN544026 }\end{array}$ \\
\hline $18 R B 17245$ & B. abortus & 4 & $\begin{array}{c}709 \\
2890\end{array}$ & $\begin{array}{l}\text { ACC to CCC } \\
\text { CGT to GGT }\end{array}$ & $\begin{array}{l}\text { Threonine to proline } \\
\text { Arginine to glycine }\end{array}$ & $\begin{array}{l}\text { MN544015, } \\
\text { MN544018, } \\
\text { MN544021, } \\
\text { MN544024, } \\
\text { MN544027 }\end{array}$ \\
\hline
\end{tabular}

Table 4. Detection of mutations in gyrA and gyrB genes associated with ciprofloxacin resistance in B. melitensis.

\begin{tabular}{|c|c|c|c|c|c|c|c|}
\hline ID & Brucella spp. & CIPResistance & Gene & Mutation Sites & Mutation & Amino Acid Change & $\begin{array}{c}\text { NCBI } \\
\text { (Accession No.) }\end{array}$ \\
\hline 18RB17230 & B. melitensis & 0.5 & \multirow{4}{*}{ gyrA } & $\begin{array}{l}167 \\
197 \\
202 \\
235\end{array}$ & $\begin{array}{l}\text { ATG to AGG } \\
\text { CCC to CGC } \\
\text { CGC to AGC } \\
\text { GGT to CGT }\end{array}$ & $\begin{array}{l}\text { Methionine to arginine } \\
\text { Proline to arginine } \\
\text { Arginine to serine } \\
\text { Glycine to arginine }\end{array}$ & MN536677 \\
\hline 18RB17235 & B. melitensis & 0.25 & & $\begin{array}{c}944,945 \\
946\end{array}$ & $\begin{array}{l}\text { GTG to GGA } \\
\text { GCC to TCC }\end{array}$ & $\begin{array}{l}\text { Valine to glycine } \\
\text { Alanine to serine }\end{array}$ & MN536678 \\
\hline 18RB17238 & B. melitensis & 0.25 & & $\begin{array}{l}941 \\
944\end{array}$ & $\begin{array}{l}\text { GCC to GAC } \\
\text { GTG to GAG }\end{array}$ & $\begin{array}{l}\text { Alanine to aspartic acid } \\
\text { Valine to glutamic acid }\end{array}$ & MN536679 \\
\hline 18RB17254 & B. melitensis & 0.12 & & 962 & AAC to ACC & Asparagine to threonine & MN536680 \\
\hline 18RB17230 & B. melitensis & 0.5 & \multirow{4}{*}{$g y r \mathrm{~B}$} & 1144 & ATC to CTC & Isoleucine to leucine & MN536681 \\
\hline 18RB17244 & B. melitensis & 0.25 & & 1141 & AAG to GAG & Lysine to Glutamine & MN536682 \\
\hline 18RB17252 & B. melitensis & 0.12 & & 1421 & TCA to TTA & Serine to Leucine & MN536683 \\
\hline 18RB17254 & B. melitensis & 0.12 & & 1421 & TCA to TTA & Serine to Leucine & MN536684 \\
\hline
\end{tabular}




\section{Discussion}

Brucellosis is a zoonotic disease of public health importance and is still endemic in many countries including Egypt $[17,20]$. In this study, the phenotypic and molecular characterization of Brucella isolates from cattle, buffaloes, sheep and goats obtained from different geographical locations of Egypt was performed. Additionally, the molecular basis of antimicrobial resistance in Brucella isolates from Egypt is reported for the first time. These results contribute to a better understanding of geographic transmission and spread of brucellae in livestock in Egypt and pave a way for specific treatment and control of the disease in animals and as well as in humans.

For the accurate diagnosis of brucellosis, isolation of bacteria or molecular proof along with suggestive clinical signs is needed. Brucellae were isolated in this study from milk, lymph nodes and fetal stomach contents as recommended in previous reports $[24,60]$.

Twenty-one B. melitensis bv3 and 8 B. abortus bv1 were isolated from cattle, buffaloes, sheep and goats from Giza, Beheria, Asyut, Qalyubia, Beni-Suef, Ismailia, Dakahlia and Monufia governorates. Previous reports were described previously that Brucella was prevailing in the country [12]. The isolation of $B$. melitensis from cattle and buffaloes in this study may be attributed to mixed farming of large and small ruminants as mentioned previously [13].

Still brucellosis is a challenge to treat in humans, particularly after delayed diagnosis of the infection. The WHO (World Health Organization) recommended treatment include high oral doses of rifampicin, doxycycline or tetracycline and trimethoprim-sulfamethoxazole. Although streptomycin and tetracycline are considered as powerful therapeutic agents against brucellosis, their higher toxicity limits their use [52,61]. Quinolones are promising alternatives to treat human brucellosis as they have good bioavailability and affinity for bone and soft tissues [51].

Only one study from Brazil reported reduced antimicrobial sensitivity in brucellae isolated from cattle [62]. However, the emergence of brucellae isolated from humans phenotypically resistant to ciprofloxacin, gentamycin, streptomycin, rifampicin and trimethoprim-sulfamethoxazole was reported in Egypt, Iran, Qatar, China, Norway and Malaysia [46,48,63-65]. Phenotypically rifampicin resistant B. melitensis isolates were also reported from Norway in imported cases from the Middle East, Asia or Africa [45]. Probable rifampicin resistance was noted in $19 \%$ of a large collection of B. melitensis isolates from humans in Egypt between 1999 to 2007 [65]. However, none of those isolates were investigated further to confirm the basis of resistance or reduced susceptibility.

In this study, a notable phenotypic resistance against ciprofloxacin $(76.19 \%)$ was detected in B. melitensis strains isolated from animals. In contrast, none of the mentioned studies reported ciprofloxacin resistance in clinical isolates of humans and animals before. However, antimicrobial resistance against quinolones has been reported in in vitro studies of B. melitensis from Greece and France [49,52].

An alarming high number of rifampicin resistant (66.66\%) B. melitensis isolates was found in this study. Previous reports from Egypt (19\%), [65], Norway (24\%) [45] and Kazakhstan (26.4\%) [66] described comparatively low resistance. Hence, these findings are in agreement with previously published reports from Egypt that clearly showed an increase in antimicrobial resistance in various other human pathogens [37]. Reduced rifampicin susceptibilities in B. melitensis strains were also reported from Iran, Malaysia, China, and Kazakhstan $[46,48,63,64,66]$.

The most striking finding of the present study was the emergence of phenotypic antimicrobial resistance against erythromycin (19.04\%), imipenem (76.19\%) and streptomycin (4.76\%) in B. melitensis isolates. However, the increased use of these antimicrobials in Egypt in veterinary and human practices may be the cause of the emerging of this resistance [37].

The phenotypic antimicrobial resistance against ciprofloxacin $(25 \%)$, erythromycin $(87.5 \%)$, imipenem (25\%) and rifampicin (37.5\%) of B. abortus isolated in this study was not proved previously. Multidrug resistant strains of $B$. abortus isolated from cattle in this study were reported previously in Brazil [62]. Four isolates of B. melitensis and one isolate of $B$. abortus showed multidrug resistance against ciprofloxacin, erythromycin, imipenem and rifampicin. These findings are in agreement with 
the results of Barbosa Pauletti et al. who find corresponding resistance among B. abortus isolates from cattle in brazil [62]. All B. melitensis and B. abortus isolates in this study were sensitive to chloramphenicol, gentamicin and tetracycline. These findings are comparable to previously published reports in Egypt, China, Qatar and Kazakhstan [46,48,65,66].

The target for rifampicin action in Brucella as well as in other bacteria is the beta-subunit of the DNA dependent RNA polymerase (RNAP) encoded by rpoB gene [47,51]. In this study, mutations were identified in rpoB gene associated with phenotypic rifampicin resistant Brucella strains isolated from clinical specimens of animals in Egypt. Mutations were detected in all phenotypically resistant brucellae. Multiple and variable mutations were noted in each isolate along with few commonly shared mutations among many isolates. Frequent mutations at positions 676, 677-TAC to CTC (tyrosine to leucine, 38\%) and 1435-AAG to CAG (lysine to glutamine, 23.8\%) in the rpoB gene of phenotypically resistant $B$. melitensis were detected. These mutations are different from previously reported mutations (in vitro mutations) associated with rifampicin resistance in Brucella [47].

Johansen et al. reported mutations in phenotypic rifampicin resistant or intermediately resistant B. melitensis isolates [45], which in agreement with the findings of this study with additional mutations were detected as well as in intermediate rifampicin resistant $B$. melitensis.

To the best of our knowledge, this study is the first report that proved mutations in the rpoB gene of rifampicin resistant B. abortus strains. Frequent mutations were detected at position 2890-CGT to GGT (arginine to glycine, 37.5\%).

Fluoroquinolone/quinolone resistance in Brucella is multifactorial by nature in addition to obvious mutations of the gyr A, gyr B, parC and parE genes [51,52]. In this study, the mutations in gyr A and gyrB genes in phenotypically resistant $B$. melitensis and B. abortus to ciprofloxacin were investigated. The mutations in gyrA did not correspond with fluoroquinolone resistance mutations described by Turkmani et al. [49], although they investigated mutations in vitro selected fluoroquinolone resistant Brucella mutants. The mutations in the $g y r$ B gene detected at positions 1141-AAG to GAG (lysine to glutamine), 1144-ATC to CTC (isoleucine to leucine) and 1421-TCA to TTA (serine to leucine) of $B$. melitensis considered as novel findings of this study. None of these mutations was detected in B. abortus strains in gyrA or gyrB genes. However, the role of parC, parE and efflux systems cannot be ruled out for fluoroquinolone resistance [51] as we did not investigate the changes in parC and parE genes.

Genes responsible for resistance against chloramphenicol (cat B), gentamicin $(A a c)$ and tetracycline (tet $\mathrm{A}$, tet $\mathrm{B}$, tet $\mathrm{M}$ and tet $\mathrm{O}$ ) were not detected in all investigated Brucella isolated in this study, which in accordance with the phenotypic antimicrobial susceptibility results of isolated Brucella isolates. It is also worth mentioning that all resistant Brucella strains were isolated from animals and they showed resistance to antimicrobials clinically used in humans practice, suggesting that the source of these Brucella strains may be of human origin. These findings point to the fact that inter-species and intra-host species Brucella transmission is common, but spillback may occur also when chronic human brucellosis is mistreated and resistant strains are shedded [67]. A likely scenario would be the animal keeper interface.

The emergence of antimicrobial resistance (AMR) in bacteria is a public health issue globally and already compromises the treatment options regarding effectiveness of antimicrobials and control of several bacterial infections especially caused by gram-negative bacteria [68]. Wide spreading AMR in these bacteria is likely to persist and even worsen in future due to the uncontrolled use of antimicrobials. Rifampicin and ciprofloxacin are effective against intracellular bacteria like Brucella [33]. Higher phenotypic resistance in Brucella against these antimicrobials is likely to limits the treatment effectiveness, owing to the increased number of infections. Emergence of multidrug resistance Brucella in livestock species in this study may pose serious threat to humans as these bacteria often transferred from animals to humans through food chain [69]. Being a zoonotic pathogen and given the emergence of increased antimicrobial resistance in Brucella species, the situation with respect to hospital care may worsen and limits the treatment options in public health settings. 


\section{Conclusions}

Brucellosis is a contagious and often communicable worldwide zoonosis with high morbidity and low mortality. There has been a tremendous increase in inter host-species infection in the recent decades, especially in developing countries when farm animal species are kept on the same premises without biosecurity precautions. The disease is endemic in Egypt and B. melitensis and B. abortus have been reported as the main causative agents of brucellosis in humans and animals. High phenotypic resistance against ciprofloxacin, erythromycin, and imipenem were detected in Brucella spp. isolated from different districts and animals species reflecting a broad geographical distribution. The molecular identification of mutations in antimicrobial resistance associated genes highlight the mechanism of resistance in Brucella spp. There is a need for further insights into the epidemiology and spread of antimicrobial resistant Brucella in Egypt. The WHO regimes have to be reevaluated and awareness among physicians about AMR needs to be raised.

Supplementary Materials: The following are available online at http://www.mdpi.com/2076-2607/7/12/603/s1, Table S1: List of primers and primer sequences used for detection of antimicrobial associated resistance mechanism.

Author Contributions: Data curation, A.U.K., W.S.S. and H.E.-A.; Investigation, A.U.K., W.S.S., A.E.S., E.S.R., A.A.M. and H.E.-A.; Methodology, A.U.K., W.S.S., A.E.S., E.S.R. and H.E.-A.; Resources, H.N., F.M. and H.E.-A.; Supervision, F.M., M.C.E., U.R., H.N. and H.E.-A.; Writing-original draft, A.U.K., A.A.M. and H.E.-A.; Writing-review \& editing, F.M., M.C.E., U.R., H.N. and H.E.-A.

Funding: This research received no external funding.

Acknowledgments: The authors thank Michaela Ganss and Katja Fischer at the Institute of Bacterial Infections and Zoonoses, Friedrich-Loeffler-Institut (FLI) for their cooperation and technical assistance. This research work was supported by the International Research Project as part of the "German biosecurity program" funded by Federal Foreign Office, Germany. The authors thank Islamic Development Bank (IDB), Jeddah, Saudi Arabia for PhD grant.

Conflicts of Interest: The authors declare that there is no conflict of interests regarding the publication of this paper.

\section{References}

1. Moreno, E. Retrospective and prospective perspectives on zoonotic brucellosis. Front. Microbiol. 2014, 5, 18. [CrossRef] [PubMed]

2. Georgi, E.; Walter, M.C.; Pfalzgraf, M.T.; Northoff, B.H.; Holdt, L.M.; Scholz, H.C.; Zoeller, L.; Zange, S.; Antwerpen, M.H. Whole genome sequencing of Brucella melitensis isolated from 57 patients in Germany reveals high diversity in strains from middle east. PLoS ONE 2017, 12, e0175425. [CrossRef] [PubMed]

3. Whatmore, A.M.; Davison, N.; Cloeckaert, A.; Al Dahouk, S.; Zygmunt, M.S.; Brew, S.D.; Perrett, L.L.; Koylass, M.S.; Vergnaud, G.; Quance, C.; et al. Brucella papionis sp. Nov., isolated from baboons (Papio spp.). Int. J. Syst. Evol. Microbiol. 2014, 64, 4120-4128. [CrossRef] [PubMed]

4. Scholz, H.C.; Revilla-Fernandez, S.; Al Dahouk, S.; Hammerl, J.A.; Zygmunt, M.S.; Cloeckaert, A.; Koylass, M.; Whatmore, A.M.; Blom, J.; Vergnaud, G.; et al. Brucella vulpis sp. Nov., isolated from mandibular lymph nodes of red foxes (Vulpes vulpes). Int. J. Syst. Evol. Microbiol. 2016, 66, 2090-2098. [PubMed]

5. Shome, R.; Kalleshamurthy, T.; Shome, B.R.; Sahay, S.; Natesan, K.; Bambal, R.G.; Sairiwal, L.; Mohandoss, N.; Barbuddhe, S.B. Lateral flow assay for brucellosis testing in multiple livestock species. J. Microbiol. Methods 2018, 148, 93-96. [CrossRef] [PubMed]

6. Morgan, W.J. Brucella classification and regional distribution. Dev. Biol. Stand. 1984, 56, 43-53.

7. Miller, M.A.; Burgess, T.L.; Dodd, E.M.; Rhyan, J.C.; Jang, S.S.; Byrne, B.A.; Gulland, F.M.; Murray, M.J.; Toy-Choutka, S.; Conrad, P.A.; et al. Isolation and characterization of a novel marine Brucella from a southern sea otter (Enhydra lutris nereis), California, USA. J. Wildl. Dis. 2017, 53, 215-227. [CrossRef]

8. Richomme, C.; Gauthier, D.; Fromont, E. Contact rates and exposure to inter-species disease transmission in mountain ungulates. Epidemiol. Infect. 2006, 134, 21-30. [CrossRef]

9. Singh, B.B.; Dhand, N.K.; Gill, J.P. Economic losses occurring due to brucellosis in Indian livestock populations. Prev. Vet. Med. 2015, 119, 211-215. [CrossRef]

10. Godfroid, J. Brucellosis in livestock and wildlife: Zoonotic diseases without pandemic potential in need of innovative one health approaches. Arch. Public Health 2017, 75, 6. [CrossRef] 
11. Refai, M. Incidence and control of brucellosis in the near east region. Vet. Microbiol. 2002, 90, 81-110. [CrossRef]

12. Menshawy, A.M.; Perez-Sancho, M.; Garcia-Seco, T.; Hosein, H.I.; Garcia, N.; Martinez, I.; Sayour, A.E.; Goyache, J.; Azzam, R.A.; Dominguez, L.; et al. Assessment of genetic diversity of zoonotic Brucella spp. Recovered from livestock in Egypt using multiple locus vntr analysis. Biomed. Res. Int. 2014, $2014,7$. [CrossRef] [PubMed]

13. Wareth, G.; Hikal, A.; Refai, M.; Melzer, F.; Roesler, U.; Neubauer, H. Animal brucellosis in Egypt. J. Infect. Dev. Ctries 2014, 8, 1365-1373. [CrossRef] [PubMed]

14. Hegazy, Y.M.; Molina-Flores, B.; Shafik, H.; Ridler, A.L.; Guitian, F.J. Ruminant brucellosis in upper Egypt (2005-2008). Prev. Vet. Med. 2011, 101, 173-181. [CrossRef] [PubMed]

15. Eltholth, M.M.; Hegazy, Y.M.; El-Tras, W.F.; Bruce, M.; Rushton, J. Temporal analysis and costs of ruminant brucellosis control programme in Egypt between 1999 and 2011. Transbound. Emerg. Dis. 2017, 64, 1191-1199. [CrossRef] [PubMed]

16. Dean, A.S.; Crump, L.; Greter, H.; Schelling, E.; Zinsstag, J. Global burden of human brucellosis: A systematic review of disease frequency. PLoS Negl. Trop. Dis. 2012, 6, e1865. [CrossRef]

17. Pappas, G.; Papadimitriou, P.; Akritidis, N.; Christou, L.; Tsianos, E.V. The new global map of human brucellosis. Lancet Infect. Dis. 2006, 6, 91-99. [CrossRef]

18. Godfroid, J.; Al Dahouk, S.; Pappas, G.; Roth, F.; Matope, G.; Muma, J.; Marcotty, T.; Pfeiffer, D.; Skjerve, E. A "one health" surveillance and control of brucellosis in developing countries: Moving away from improvisation. Comp. Immunol. Microbiol. Infect. Dis. 2013, 36, 241-248. [CrossRef]

19. Tuon, F.F.; Gondolfo, R.B.; Cerchiari, N. Human to human transmission of Brucella-A systematic review. Trop. Med. Int. Health 2017, 22, 539-546. [CrossRef]

20. El-Diasty, M.; Wareth, G.; Melzer, F.; Mustafa, S.; Sprague, L.D.; Neubauer, H. Isolation of Brucella abortus and Brucella melitensis from seronegative cows is a serious impediment in brucellosis control. Vet. Sci. 2018, 5, 4. [CrossRef]

21. Godfroid, J.; Nielsen, K.; Saegerman, C. Diagnosis of brucellosis in livestock and wildlife. Croat. Med. J. 2010, 51, 296-305. [CrossRef] [PubMed]

22. Mathew, C.; Stokstad, M.; Johansen, T.B.; Klevar, S.; Mdegela, R.H.; Mwamengele, G.; Michel, P.; Escobar, L.; Fretin, D.; Godfroid, J. First isolation, identification, phenotypic and genotypic characterization of Brucella abortus biovar 3 from dairy cattle in Tanzania. BMC Vet. Res. 2015, 11, 9. [CrossRef] [PubMed]

23. Vicente, A.F.; Antunes, J.M.; Lara, G.H.; Mioni, M.S.; Allendorf, S.D.; Peres, M.G.; Appolinario, C.M.; Listoni, F.J.; Ribeiro, M.G.; Megid, J. Evaluation of three formulations of culture media for isolation of Brucella spp. Regarding their ability to inhibit the growth of contaminating organisms. Biomed. Res. Int. 2014, $2014,3$. [CrossRef] [PubMed]

24. Alton, G.G.; Jones, L.M.; Angus, R.D.; Verger, J.M. Techniques for the Brucellosis Laboratory; Institut National De La Recherche Agronomique: Paris, France, 1988; Available online: https://www.cabi.org/isc/abstract/ 19892297928 (accessed on 19 November 2019).

25. Angeletti, S. Matrix assisted laser desorption time of flight mass spectrometry (maldi-tof ms) in clinical microbiology. J. Microbiol. Method 2017, 138, 20-29. [CrossRef] [PubMed]

26. Patel, R. Maldi-tof ms for the diagnosis of infectious diseases. Clin. Chem. 2015, 61, 100-111. [CrossRef] [PubMed]

27. Sali, M.; De Maio, F.; Tarantino, M.; Garofolo, G.; Tittarelli, M.; Sacchini, L.; Zilli, K.; Pasquali, P.; Petrucci, P.; Marianelli, C.; et al. Rapid and safe one-step extraction method for the identification of Brucella strains at genus and species level by maldi-tof mass spectrometry. PLoS ONE 2018, 13, e0197864. [CrossRef]

28. Hinic, V.; Brodard, I.; Thomann, A.; Cvetnic, Z.; Makaya, P.V.; Frey, J.; Abril, C. Novel identification and differentiation of Brucella melitensis, $b$. Abortus, $b$. Suis, $b$. Ovis, $b$. Canis, and $b$. Neotomae suitable for both conventional and real-time pcr systems. J. Microbiol. Methods 2008, 75, 375-378. [CrossRef]

29. Bricker, B.J.; Halling, S.M. Differentiation of Brucella abortus bv. 1, 2, and 4, Brucella melitensis, Brucella ovis, and Brucella suis bv. 1 by pcr. J. Clin. Microbiol. 1994, 32, 2660-2666.

30. Lopez-Goni, I.; Garcia-Yoldi, D.; Marin, C.M.; de Miguel, M.J.; Munoz, P.M.; Blasco, J.M.; Jacques, I.; Grayon, M.; Cloeckaert, A.; Ferreira, A.C.; et al. Evaluation of a multiplex pcr assay (bruce-ladder) for molecular typing of all Brucella species, including the vaccine strains. J. Clin. Microbiol. 2008, 46, 3484-3487. [CrossRef] 
31. Ali, S.; Ali, Q.; Melzer, F.; Khan, I.; Akhter, S.; Neubauer, H.; Jamal, S.M. Isolation and identification of bovine Brucella isolates from pakistan by biochemical tests and pcr. Trop. Anim Health Prod. 2014, 46, 73-78. [CrossRef]

32. Bricker, B.J.; Halling, S.M. Enhancement of the Brucella amos pcr assay for differentiation of Brucella abortus vaccine strains s19 and rb51. J. Clin. Microbiol. 1995, 33, 1640-1642. [PubMed]

33. Ariza, J.; Bosilkovski, M.; Cascio, A.; Colmenero, J.D.; Corbel, M.J.; Falagas, M.E.; Memish, Z.A.; Roushan, M.R.; Rubinstein, E.; Sipsas, N.V.; et al. Perspectives for the treatment of brucellosis in the 21st century: The Ioannina recommendations. PLoS Med. 2007, 4, e317. [CrossRef]

34. Del Pozo, J.S.G.; Solera, J. Treatment of human brucellosis-review of evidence from clinical trials. In Updates on Brucellosis; InTech.Open: London, UK, 2015.

35. Zakaa El-Din, M.; Samy, F.; Mohamed, A.; Hamdy, F.; Yasser, S.; Ehab, M. Egyptian community pharmacists' attitudes and practices towards antibiotic dispensing and antibiotic resistance; a cross-sectional survey in greater Cairo. Curr. Med. Res. Opin. 2019, 35, 939-946. [CrossRef] [PubMed]

36. Sabry, N.A.; Farid, S.F.; Dawoud, D.M. Antibiotic dispensing in Egyptian community pharmacies: An observational study. Res. Soc. Adm. Pharm. 2014, 10, 168-184. [CrossRef] [PubMed]

37. World Health Organization, Regional Office for the Eastern Mediterranean. Report on the Consultative Meeting on Antimicrobial Resistance for Countries in the Eastern Mediterranean Region: From Policies to Action; World Health Organization, Regional Office for the Eastern Mediterranean: Sharm el Sheikh, Egypt, 2013.

38. Abdulah, R. Antibiotic abuse in developing countries. Pharm. Regul. Aff. 2012, 1, 1000-1006. [CrossRef]

39. Kasim, K.; Hassan, H. Self medication problem in Egypt: A review of current and future perspective. Int. J. Cur. Res. Rev. 2018, 10, 6.

40. Gebeyehu, E.; Bantie, L.; Azage, M. Inappropriate use of antibiotics and its associated factors among urban and rural communities of bahir dar city administration, northwest ethiopia. PLoS ONE 2015, 10, e0138179. [CrossRef]

41. Magiorakos, A.P.; Srinivasan, A.; Carey, R.B.; Carmeli, Y.; Falagas, M.E.; Giske, C.G.; Harbarth, S.; Hindler, J.F.; Kahlmeter, G.; Olsson-Liljequist, B.; et al. Multidrug-resistant, extensively drug-resistant and pandrug-resistant bacteria: An international expert proposal for interim standard definitions for acquired resistance. Clin. Microbiol. Infect. 2012, 18, 268-281. [CrossRef]

42. Landers, T.F.; Cohen, B.; Wittum, T.E.; Larson, E.L. A review of antibiotic use in food animals: Perspective, policy, and potential. Public Health Rep. 2012, 127, 4-22. [CrossRef]

43. Agunos, A.; Pierson, F.W.; Lungu, B.; Dunn, P.A.; Tablante, N. Review of nonfoodborne zoonotic and potentially zoonotic poultry diseases. Avian Dis. 2016, 60, 553-575. [CrossRef]

44. Hoffman, S.J.; Outterson, K.; Rottingen, J.A.; Cars, O.; Clift, C.; Rizvi, Z.; Rotberg, F.; Tomson, G.; Zorzet, A. An international legal framework to address antimicrobial resistance. Bull. World Health Organ. 2015, 93, 1. [CrossRef] [PubMed]

45. Johansen, T.B.; Scheffer, L.; Jensen, V.K.; Bohlin, J.; Feruglio, S.L. Whole-genome sequencing and antimicrobial resistance in Brucella melitensis from a Norwegian perspective. Sci Rep. 2018, 8, 9. [CrossRef] [PubMed]

46. Liu, Z.G.; Di, D.D.; Wang, M.; Liu, R.H.; Zhao, H.Y.; Piao, D.R.; Zhao, Z.Z.; Hao, Y.Q.; Du, Y.N.; Jiang, H.; et al. In vitro antimicrobial susceptibility testing of human Brucella melitensis isolates from Ulanqab of inner Mongolia, China. BMC Infect. Dis. 2018, 18, 6. [CrossRef] [PubMed]

47. Marianelli, C.; Ciuchini, F.; Tarantino, M.; Pasquali, P.; Adone, R. Genetic bases of the rifampin resistance phenotype in Brucella spp. J. Clin. Microbiol. 2004, 42, 5439-5443. [CrossRef] [PubMed]

48. Deshmukh, A.; Hagen, F.; Sharabasi, O.A.; Abraham, M.; Wilson, G.; Doiphode, S.; Maslamani, M.A.; Meis, J.F. In vitro antimicrobial susceptibility testing of human Brucella melitensis isolates from Qatar between 2014-2015. BMC Microbiol. 2015, 15, 5. [CrossRef] [PubMed]

49. Turkmani, A.; Psaroulaki, A.; Christidou, A.; Chochlakis, D.; Tabaa, D.; Tselentis, Y. In vitro-selected resistance to fluoroquinolones in two Brucella strains associated with mutational changes in Gyra. Int. J. Antimicrob. Agents 2008, 32, 227-232. [CrossRef]

50. Biswas, S.; Raoult, D.; Rolain, J.M. A bioinformatic approach to understanding antibiotic resistance in intracellular bacteria through whole genome analysis. Int. J. Antimicrob. Agents 2008, 32, 207-220. [CrossRef] 
51. Valdezate, S.; Navarro, A.; Medina-Pascual, M.J.; Carrasco, G.; Saez-Nieto, J.A. Molecular screening for rifampicin and fluoroquinolone resistance in a clinical population of Brucella melitensis. J. Antimicrob. Chemother. 2010, 65, 51-53. [CrossRef]

52. Ravanel, N.; Gestin, B.; Maurin, M. In vitro selection of fluoroquinolone resistance in brucella melitensis. Int. J. Antimicrob. Agents 2009, 34, 76-81. [CrossRef]

53. OIE. Brucellosis (Brucella abortus, B. melitensis and B. suis) (infection with B. abortus, B. melitensis and B. suis). In Manual of Diagnostic Tests and Vaccines for Terrestrial Animals 2019, OIE; World Health Organization for Animal Health: Paris, France, 2019; pp. 355-398.

54. Karger, A.; Melzer, F.; Timke, M.; Bettin, B.; Kostrzewa, M.; Nockler, K.; Hohmann, A.; Tomaso, H.; Neubauer, H.; Al Dahouk, S. Interlaboratory comparison of intact-cell matrix-assisted laser desorption ionization-time of flight mass spectrometry results for identification and differentiation of Brucella spp. J. Clin. Microbiol. 2013, 51, 3123-3126. [CrossRef]

55. Baily, G.G.; Krahn, J.B.; Drasar, B.S.; Stoker, N.G. Detection of Brucella melitensis and Brucella abortus by DNA amplification. J. Trop. Med. Hyg. 1992, 95, 271-275. [PubMed]

56. Garcia-Yoldi, D.; Marin, C.M.; de Miguel, M.J.; Munoz, P.M.; Vizmanos, J.L.; Lopez-Goni, I. Multiplex pcr assay for the identification and differentiation of all Brucella species and the vaccine strains Brucella abortus s19 and rb51 and Brucella melitensis rev1. Clin. Chem. 2006, 52, 779-781. [CrossRef] [PubMed]

57. CLSI. Clinical and Laboratory Standard Institute: Performance Standards for Antimicrobial Susceptibility Testing, 29th ed.; CLSI: Wayne, PA, USA, 2019.

58. EUCAST. The European Committee on Antimicrobial Susceptibility Testing. Breakpoint Tables for Interpretation of Mics and Zone Diameters 2019, Version 9.0. 2019. Available online: http://www.eucast.org (accessed on 19 November 2019).

59. Khazaei, Z.; Najafi, A.; Piranfar, V.; Mirnejad, R. Microarray-based long oligonucleotides probe designed for Brucella spp. Detection and identification of antibiotic susceptibility pattern. Electron. Physician 2016, 8, 2297-2303. [CrossRef] [PubMed]

60. Mugizi, D.R.; Muradrasoli, S.; Boqvist, S.; Erume, J.; Nasinyama, G.W.; Waiswa, C.; Mboowa, G.; Klint, M.; Magnusson, U. Isolation and molecular characterization of Brucella isolates in cattle milk in Uganda. Biomed. Res. Int. 2015. [CrossRef]

61. Trott, D.J.; Abraham, S.; Adler, B. Antimicrobial resistance in Leptospira, Brucella, and other rarely investigated veterinary and zoonotic pathogens. Microbiol. Spectr. 2018, 6, 13. [CrossRef]

62. Barbosa Pauletti, R.; Reinato Stynen, A.P.; Pinto da Silva Mol, J.; Seles Dorneles, E.M.; Alves, T.M.; de Sousa Moura Souto, M.; Minharro, S.; Heinemann, M.B.; Lage, A.P. Reduced susceptibility to rifampicin and resistance to multiple antimicrobial agents among Brucella abortus isolates from cattle in brazil. PLoS ONE 2015, 10, e0132532. [CrossRef]

63. Torkaman Asadi, F.; Hashemi, S.H.; Alikhani, M.Y.; Moghimbeigi, A.; Naseri, Z. Clinical and diagnostic aspects of brucellosis and antimicrobial susceptibility of Brucella isolates in Hamedan, Iran. Jpn. J. Infect. Dis. 2017, 70, 235-238. [CrossRef]

64. Hashim, R.; Ahmad, N.; Mohamed Zahidi, J.; Tay, B.Y.; Mohd Noor, A.; Zainal, S.; Hamzah, H.; Hamzah, S.H.; Chow, T.S.; Wong, P.S.; et al. Identification and in vitro antimicrobial susceptibility of Brucella species isolated from human brucellosis. Int. J. Microbiol. 2014, 2014, 5. [CrossRef]

65. Abdel-Maksoud, M.; House, B.; Wasfy, M.; Abdel-Rahman, B.; Pimentel, G.; Roushdy, G.; Dueger, E. In vitro antibiotic susceptibility testing of Brucella isolates from Egypt between 1999 and 2007 and evidence of probable rifampin resistance. Ann. Clin. Microbiol. Antimicrob. 2012, 11, 24. [CrossRef]

66. Shevtsov, A.; Syzdykov, M.; Kuznetsov, A.; Shustov, A.; Shevtsova, E.; Berdimuratova, K.; Mukanov, K.; Ramankulov, Y. Antimicrobial susceptibility of Brucella melitensis in Kazakhstan. Antimicrob. Resist. Infect. Control. 2017, 6, 5. [CrossRef]

67. Khan, M.Z.; Zahoor, M. An overview of brucellosis in cattle and humans, and its serological and molecular diagnosis in control strategies. Trop. Med. Infect. Dis. 2018, 3, 14. [CrossRef] [PubMed] 
68. Theuretzbacher, U. Global antimicrobial resistance in gram-negative pathogens and clinical need. Curr. Opin. Microbiol. 2017, 39, 106-112. [CrossRef] [PubMed]

69. Asai, T.; Hiki, M.; Ozawa, M.; Koike, R.; Eguchi, K.; Kawanishi, M.; Kojima, A.; Endoh, Y.S.; Hamamoto, S.; Sakai, M.; et al. Control of the development and prevalence of antimicrobial resistance in bacteria of food animal origin in japan: A new approach for risk management of antimicrobial veterinary medicinal products in Japan. Foodborne Pathog. Dis. 2014, 11, 171-176. [CrossRef] [PubMed] 